\title{
Glial swelling following human cerebral contusion: an ultrastructural study
}

\author{
R Bullock, W L Maxwell, D I Graham, G M Teasdale, J H Adams
}

\begin{abstract}
The ultrastructural features of cerebral contusion seen three hours to 11 days after head injury were studied in 18 patients undergoing surgery. Massive astrocytic swelling ("cytotoxic" oedema) was seen three hours to three days after injury, maximal in perivascular foot processes, and compressing some of the underlying capillaries. The tight junctions were not disrupted. Neuronal damage was most marked three to 11 days after injury. The pathophysiological mechanisms leading to oedema formation and neuronal degeneration are discussed.
\end{abstract}

Cerebral cortical contusions are generally regarded as the pathological hallmark of head injury and are clinically important for several reasons. ${ }^{1-5}$ Extensive swelling of the cortical ribbon and underlying white matter may occur acutely after cerebral contusions and may cause mass effect, brain shift and raised intracranial pressure, and these events may cause secondary ischaemic brain damage or death. ${ }^{6}$ When widespread, contusions cause extensive destruction of the cortical ribbon particularly at the tips of the temporal and frontal lobes and the orbital surface of the frontal lobes, and this may lead to post traumatic epilepsy, and to the neuropsychological and behavioural sequelae, typical of severe head injury. ${ }^{?}$

Although previous studies have focused upon the pathogenesis, ${ }^{45}$ histopathology, ${ }^{1}$ distribution $^{13}$ and quantification of cerebral contusion, many aspects remain unresolved. ${ }^{3}$ Why do some cerebral contusions swell and generate raised intracranial pressure, while others do not? What proportion of the neuronal necrosis which is seen adjacent to cerebral contusions is due to primary contact damage, and how much of it is due to secondary factors, such as delayed reduction in blood flow to the contused area?

In studies in which we have mapped cerebral blood flow following human cerebral

Table $1 A$ Control patients-clinical data

\begin{tabular}{|c|c|c|c|}
\hline Case & $\begin{array}{l}\text { Age } \\
\text { (years) }\end{array}$ & Tissue biopsied & Indication for surgery \\
\hline 1 & 65 & \multirow{2}{*}{$\begin{array}{l}\text { Cortex and white matter right } \\
\text { temporal tip } \\
\text { Left frontal cortex }\end{array}$} & Deep temporal glioma, seizures \\
\hline 2 & 56 & & $\begin{array}{l}\text { Partial left frontal lobectomy for } \\
\text { glioma }\end{array}$ \\
\hline 3 & 36 & \multirow{2}{*}{$\begin{array}{l}\text { Posterior right temporal cortex and } \\
\text { white matter } \\
\text { Right temporal cortex }\end{array}$} & Right temporal lobectomy for glioma \\
\hline 4 & 22 & & $\begin{array}{l}\text { Right temporal lobectomy for severe } \\
\text { epilepsy }\end{array}$ \\
\hline
\end{tabular}

contusion, zones of profoundly reduced regional blood flow (rCBF) have been found adjacent to contusions, and this may be a factor in the ischaemic neuronal necrosis which is a prominent finding in pathological studies. Alterations to the microvascular bed adjacent to cerebral contusion may therefore be an important determinant of such changes. ${ }^{8}$

The purpose of this study was to determine ultrastructurally the changes in neuronal, glial and microvascular morphology which occur with time following human cerebral contusion, and to determine their role in the pathogenic processes which are known to damage the brain after severe head injury.

\section{Patients and methods}

Eighteen patients with severe cerebral contusion were studied. Clinical details are shown in table $1 \mathrm{~B}$. In each patient, contusions were shown on CT scan, and in seven patients, mass effect, acute clinical deterioration and associated haematomas necessitated urgent operation, at which the contusion was resected, and biopsy taken from the margins of the resected tissue. In a further four patients, ICP monitoring was initially performed to ascertain the need to remove the contusion, and ICP rose necessitating surgery. In the remaining seven patients, delayed neurological deterioration occurred up to 11 days after injury, precipitating the operation. Specimens of resected cerebral contusion from these patients were compared with specimens processed in an identical manner, from four control patients, with macroscopically and radiologically normal brain tissue at the site of biopsy, who had either temporal lobectomy for epilepsy or resection of deep temporal glioma. Clinical details of these patients are shown in table 1A. Rongeur specimens around 2 cubic $\mathrm{mm}$ in size were taken from contused grey and white matter and immediately immersed in buffered glutaraldehyde $(350 \mathrm{~m}$ osm). Specimens were then stored at $4^{\circ} \mathrm{C}$ for two to seven days until processing for electronmicroscopy. The site from which the biopsy was taken was recorded by the surgeon and related as closely as possible to the CT appearance on the pre-operative scan. The study was approved by the Ethics Committee of the Institute of Neurological Sciences, Glasgow.

\section{Processing for electronmicroscopy}

After immersion fixation, specimens were cut into $200 \mu$ thick sections using a vibrotome, and ultrasonicated to dislodge non-adherent blood components from the vessel lumina. 
Table 1B Patients with cerebral contusion-clinical data

\begin{tabular}{|c|c|c|c|}
\hline Case & $\begin{array}{l}\text { Age } \\
\text { (years) }\end{array}$ & $\begin{array}{l}\text { Interval between } \\
\text { injury and biopsy }\end{array}$ & $C T$ diagnosis and clinical details \\
\hline 1 & 67 & 3 hours & $\begin{array}{l}\text { Fall. Right temporal contusion, small acute subdural } \\
\text { haematoma, hemispheric swelling, high ICP (died) }\end{array}$ \\
\hline 2 & 33 & 6 hours & $\begin{array}{l}\text { Fall. Right frontal lobectomy for massive brain swelling } \\
\text { when acute subdural haematoma removed. (Alcoholic with } \\
\text { clotting defect-died) }\end{array}$ \\
\hline 3 & 68 & 13 hours & $\begin{array}{l}\text { RTA. Right temporal contusion with deterioration of } \\
\text { consciousness. Good recovery }\end{array}$ \\
\hline 4 & 18 & 16 hours & $\begin{array}{l}\text { RTA. Large traumatic, right frontal intracerebral } \\
\text { haematoma and overlying contusion, deterioration of } \\
\text { consciousness. Good recovery }\end{array}$ \\
\hline 5 & 52 & 17 hours & $\begin{array}{l}\text { Found unconscious and drunk. Left temporal contusion } \\
\text { ("Burst lobe") and acute subdural haematoma. Disabled }\end{array}$ \\
\hline 6 & 18 & 23 hours & $\begin{array}{l}\text { RTA. Bifrontal contusions. Left frontal intracerebral } \\
\text { haematoma, deteriorating consciousness. Disabled }\end{array}$ \\
\hline 7 & 29 & 27 hours & $\begin{array}{l}\text { Assault. Focal right parietal contusion and depressed } \\
\text { fracture. Good recovery }\end{array}$ \\
\hline 8 & 17 & 28 hours & $\begin{array}{l}\text { RTA. Left hemispheric swelling and temporal } \\
\text { contusions-ICP monitoring } \rightarrow \text { high ICP. Disabled }\end{array}$ \\
\hline 9 & 59 & 31 hours & $\begin{array}{l}\text { RTA. Acute right extradural, subdural haematomas and } \\
\text { right frontal contusion. Deteriorating consciousness. } \\
\text { Disabled }\end{array}$ \\
\hline 10 & 55 & 33 hours & $\begin{array}{l}\text { Fell while drunk. Delayed deterioration. Coma. Bifrontal } \\
\text { contusions. Thin left acute subdural haematoma. Good } \\
\text { recovery }\end{array}$ \\
\hline 11 & 68 & 37 hours & $\begin{array}{l}\text { RTA. Right temporal contusion, small acute subdural. } \\
\text { ICP monitoring } \rightarrow \text { high ICP. Good recovery }\end{array}$ \\
\hline 12 & 42 & 42 hours & $\begin{array}{l}\text { Found unconscious. Delayed deterioration. Bitemporal } \\
\text { contusions. This left acute subdural. Good recovery }\end{array}$ \\
\hline 13 & 46 & 44 hours & $\begin{array}{l}\text { Fall. Delayed confusion. Right temporal contusion. ICP } \\
\text { monitoring } \rightarrow \text { high ICP. Good recovery }\end{array}$ \\
\hline 14 & 59 & 49 hours & $\begin{array}{l}\text { Alcoholic epileptic. ? Fall. Delayed confusion. Bifrontal } \\
\text { contusions, mass effect. Disabled }\end{array}$ \\
\hline 15 & 40 & 72 hours & $\begin{array}{l}\text { Fall. Right parietal acute subdural. Delayed ICP rise } \rightarrow \\
\text { new low density. Right temporal } \rightarrow \text { re-opening craniotomy } \\
\text { and right temporal lobectomy. Disabled }\end{array}$ \\
\hline 16 & 64 & 77 hours & $\begin{array}{l}\text { Fall. Multiple contusions. Left hemisphere, small } \\
\text { extradural haematoma. Right parietal. Delayed } \\
\text { deterioration. Partial left temporal lobectomy. Disabled }\end{array}$ \\
\hline 17 & 44 & 5 days & $\begin{array}{l}\text { Hydrocephalic with shunt. Fell out of bed } \rightarrow \text { bifrontal } \\
\text { contusions. Delayed coma. ICP high. Right frontal } \\
\text { contusion evacuated. Disabled }\end{array}$ \\
\hline 18 & 72 & 11 days & $\begin{array}{l}\text { Fall. Persistently confused. Right frontal subacute } \\
\text { subdural, small temporal contusion. (Burst lobe at } \\
\text { surgery). Disabled }\end{array}$ \\
\hline
\end{tabular}

Specimens were then fixed in $2 \%$ osmium tetroxide in phosphate buffer, and the slices were critical-point dried, mounted on scanning electronmicroscopy stubs with silver paint and sputter-coated before viewing in a JEOL 300 TS scanning electronmicroscope. Blood vessels were selected for particular study and micrographs were taken at a magnification of 7000 and 1500 times to allow demonstration of endothelial surface structure and measure vessel size. After scanning electronmicroscopy specimens were carefully removed from the SEM stubs and washed three times in $100 \%$ acetone to remove the silver paint. The material was then embedded in araldite resin and cut into semi-thin sections stained with toluidine blue and areas of

Table 2 The time intervals for various EM features after cerebral contusion

\begin{tabular}{ll}
\hline $\begin{array}{l}\text { Time interval at which EM } \\
\text { occurred after injury }\end{array}$ & EM feature \\
\hline 3 hours-3 days & Astrocyte swelling \\
3 hours-3 days & Astrocyte podocyte swelling \\
3 hours-3 days & Astrocytc podocyte disruption \\
3 hours-7 days & Vessel lumen compression \\
3 hours-5 days & "Swiss cheese vacuolation" of neuropil on TM \\
3,16 hours & Red cell diapedesis \\
6 hours-3 days & Endothelial fenestration on SEM \\
16 hours-3 days & Intravascular clots adherent to walls \\
16 hours-3 days & Gross tissue disruption + haemorrhage \\
16 hours-5 days & White matter "loosening" \\
16 hours-11 days & Peri-vascular red cells \\
$3-11$ days & Pyknosis of neurons \\
$5-7$ days & Sheet reaction-glycogen granules \\
5,11 days & Leucocytic phageocytosis \\
11 days & Collagen deposition \\
\hline
\end{tabular}

interest selected for transmission electronmicroscopy. Thin sections were cut for the transmission EM and routinely stained with lead citrate and uranyl acetate and examined in a JEOL $100 \mathrm{~S}$ transmission electronmicroscope.

\section{Results}

Biopsies were obtained at time points ranging from three hours to 11 days after injury. In all the specimens the quality of fixation as judged by preservation of intracellular organelles was acceptable.

\section{Control patients}

Normal glial, neuronal and vascular ultrastructure was present in all control patients, and the neuropil and white matter density was normal (fig 1). Scanning electronmicroscopy demonstrated pit-vesicle activity on the endothelial surface of the lumen of all vessels in the control patients (table 2).

Transmission EM findings in patients with cerebral contusion

A) GROSS DISRUPTION OF TISSUE

In five specimens taken from three patients the architecture of the cortical neuropil was disrupted by red blood cells and plasma. Whenever this was seen, the adjacent neuropil was grossly abnormal, demonstrating marked vacuolation and lucency of astrocyte cytoplasm (fig 2).

\section{B) GLIAL CELL SWELLING}

The most consistent finding in both grey and white matter in patients with cerebral contusions was severe swelling affecting particularly astrocytes. This was associated with "loosening" and apparent pseudo-vacuolation of the neuropil to produce a "Swiss cheese" appearance, particularly striking on SEM. This appearance developed rapidly (figs 3, 4a) within three hours of injury but was still present in specimens taken three days after

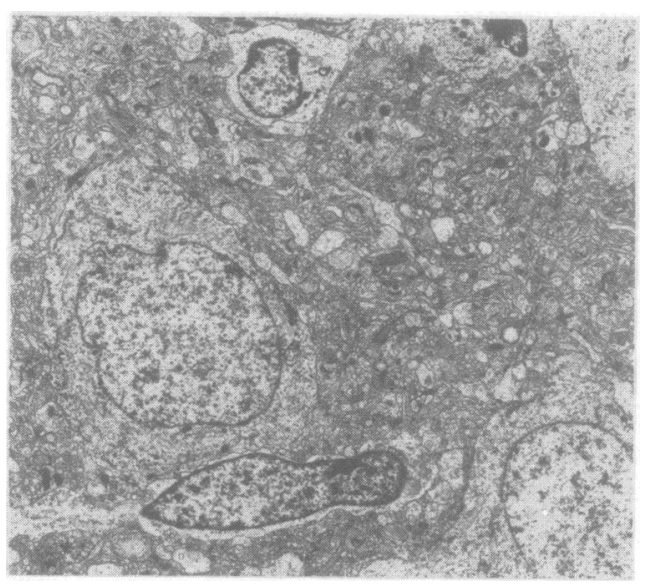

Figure 1 Thin section of cortical neuropil from control patient KW. Preservation of intracytoplasmic organelles is satisfactory and vacuolation of neuropil is absent.

(Magnification: $\times$ 2975). 
Figure 2 Thin section through cortical neuropil 16 hours after injury. Note gross swelling of astrocytic cytoplasm (lower right) and vacuolation of neuropil caused by swelling astrocytic process. Note mitochondria apparently lying free within the cytoplasm of swollen astrocytes (arrow). (Magnification: $\times$ 5250).

Figure 3 Scanning EM of a section through cortical neuropil to show vacuolation surrounding a blood vessel (arrow)

("Swiss cheese"

appearance).

(Magnification: $\times 1000$ ).
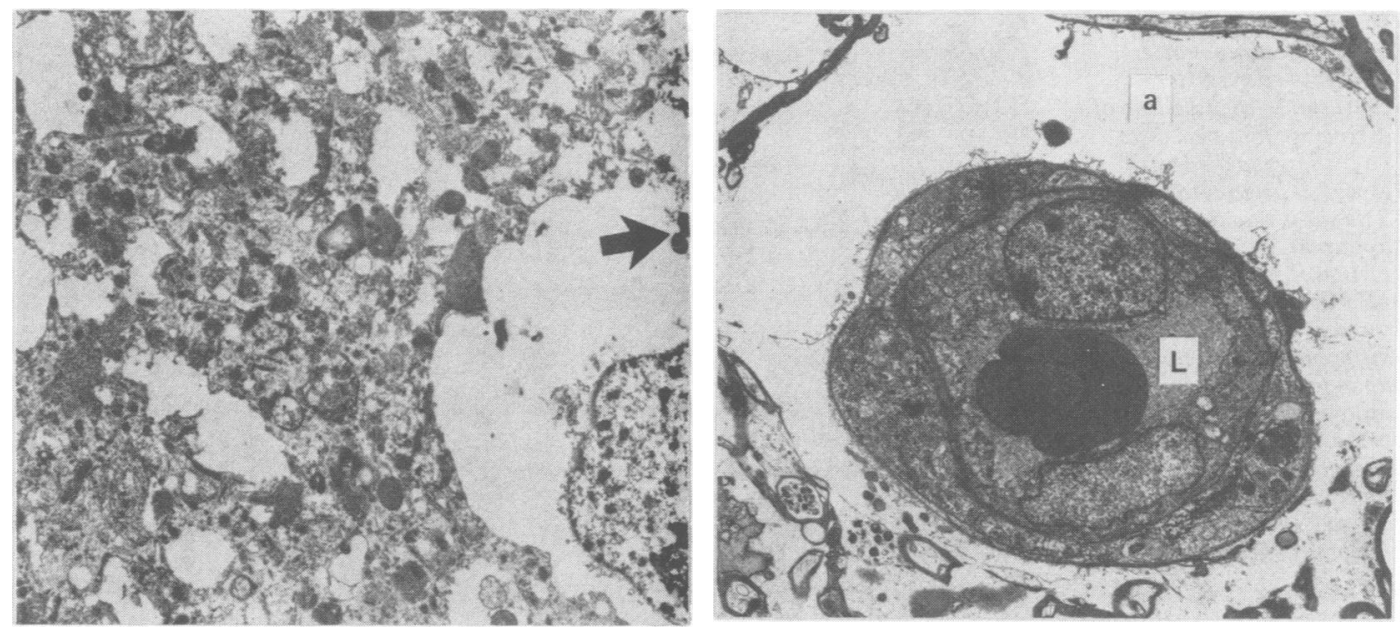

Figure 5 Thin section through white matter capillary showing gross astrocytic foot process swelling (a), with disruption of the foot process limiting membranes and narrowing and compression of vessel lumen $(L)$. (Magnification: $\times 3750$ ).

C) SWELLING OF PERIVASCULAR PODOCYTIC PROCESSES

Swelling of astrocytic perivascular podocytic processes were the most obvious manifestation of glial swelling. This was sufficiently severe to suggest compression of the adjacent vessel lumen in some cases (fig $4 a, b$ ). Disruption of foot processes was seen in some specimens taken at periods from three hours to three days after injury (fig 5). In specimens which were taken at later periods after injury, astrocytic swelling appeared to be less extensive and at five days astrocytic processes contained glycogen deposits and pseudopodial folds typical of the "sheet reaction" of Torvick (fig $6 \mathrm{a}, \mathrm{b}$ ). ${ }^{9}$ Comparison between the changes seen in cortex (fig $4 a, b$ ) and those in white matter (figs $4,5,6$ ) should, however, be made with caution. recognisable. In the specimens taken five days after injury, astrocytic swelling was less marked although still apparent (fig 6a, b) and the astrocytes now contained deposits of glycogen, typical of the "sheet reaction" described by Torvick (fig 6$)^{9}$

D) VASCULAR CHANGES (TRANSMisSion ELECTRONMICROSCOPY)

In the majority of vessels seen within con-

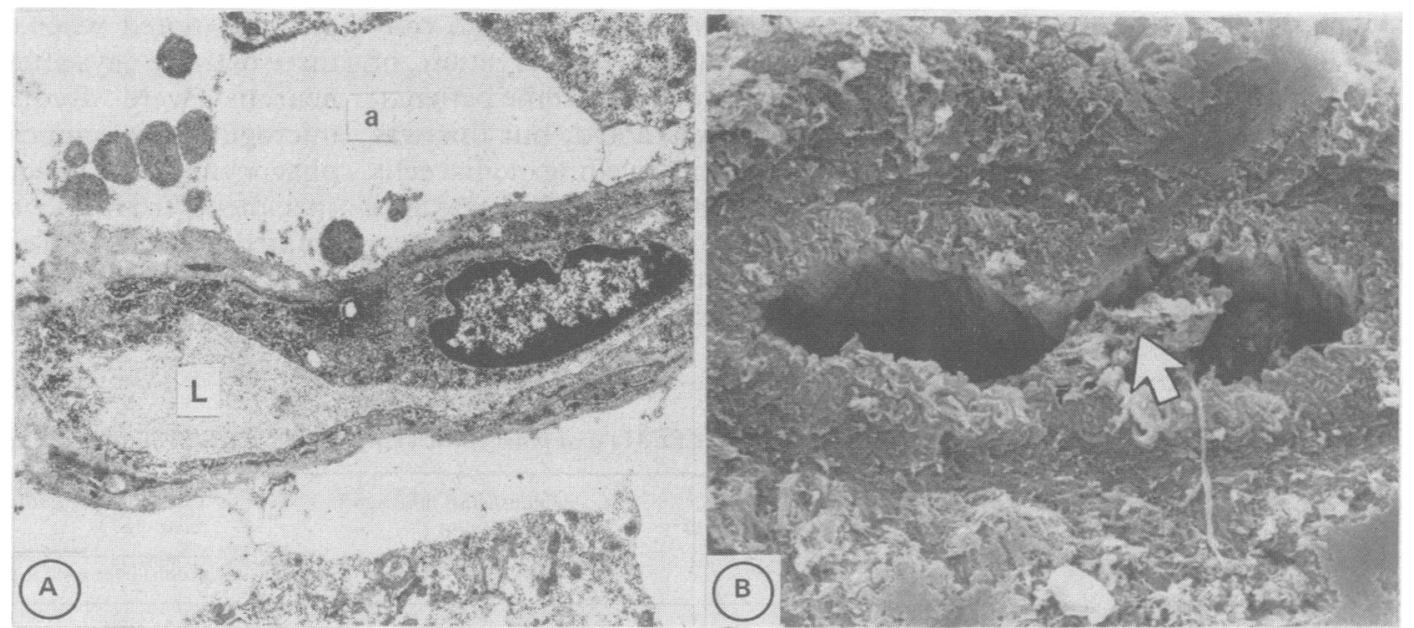

Figure 4 (A) Thin section through a cortical capillary, showing flattening of vessel lumen (L) and massive swelling of perivascular astrocytic foot processes (a). The lumen is narrowed to such an extent that passage of red cells would be impossible. (Magnification: $\times 10$ 500); (B) Scanning EM preparation of a larger blood vessel in cortical neuropil showing collapse of the vessel lumen and folding of the tunica intima with adherent clot (arrow).

(Magnification: $\times$ 460). 
Figure 6 (A) Thin section of white matter taken five days after contusion-the swelling of astrocytic foot processes (a) is less marked with glycogen accumulation. The sheet reaction is apparent.

(Magnification: $\times 8200)$; (B) Thin section of cortical neuropil in a different patient, operated upon five days after head injury. Swollen astrocyte processes and accumulation of glycogen granules therein are seen. (The socalled "sheet reaction"). (Magnification: $\times$ 8750).

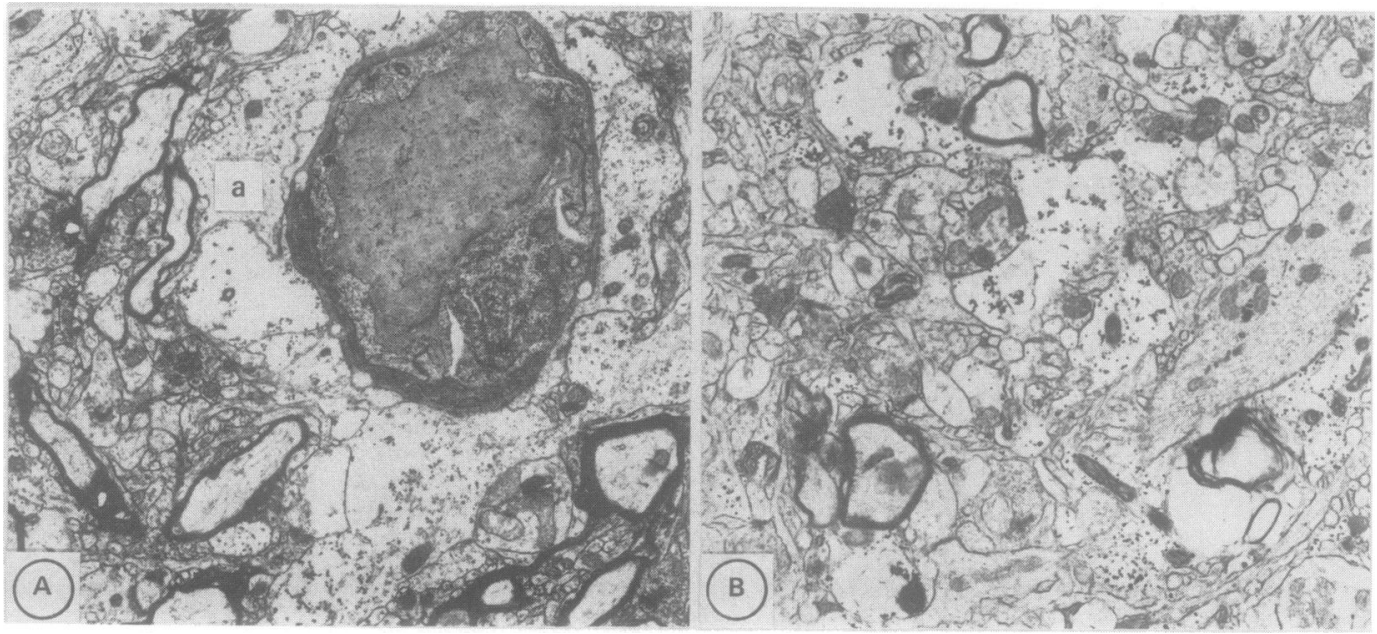

tused tissue, endothelial cell morphology was grossly normal and in those vessels where adjacent astrocytic swelling was not noticed, vessel lumina were not disrupted or occluded. No disruption of inter-endothelial tight junctions was noted, and in the majority of vessels studied, the morphology of the perivascular basement membrane was also normal.

An increased number of cytoplasmic folds and processes on the luminal aspects of endothelium were seen within vessels and thin transmission sections showed a very irregular luminal profile to the endothelium at two days (fig 7). Inter-endothelial junctions were not disrupted despite gross disruption of the adjacent neuropil. This irregular endothelial profile was also seen at five days when the astrocytic sheet reaction had become well established (fig 8). ${ }^{9}$

Counts of endothelial pinocytotic vesicles in the vessels from contusion specimens taken at different times after injury, showed a decline with time and the highest numbers of vesicles were seen in the control and acute patients (table 3).

Early white matter changes on transmission EM Twelve specimens of white matter from contused tissue were studied. Preservation of myelin was remarkably good. In some patients, swelling of axoplasm was noted, but this was never severe. Cytoplasmic swelling of glial cells within white matter was present but was less marked than that seen in the grey matter. Accumulation of interstitial fluid within white matter was marked (fig 5).

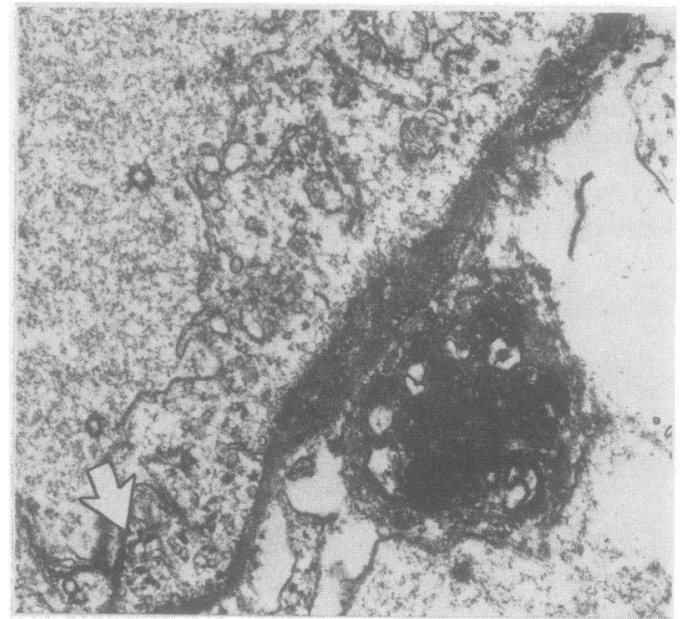

Figure 7 High magnification thin section of part of a vessel wall two days after injury to show a thickened irregular profile of the endothelium. Microvilli are present. Note that the interendothelial tight junctions are intact (arrow). Astrocytic foot processes on the abluminal surface of the basal lamina are grossly swollen.

(Magnification: $\times 20$ 000)

\section{Delayed changes}

\section{A PYKNOSIS AND SHRINKAGE}

Pyknosis and shrinkage of both neurons and glia was noted when biopsies were taken at three or more days after injury (fig 9). Pyknotic neurons were frequently surrounded by microglia which appeared to be carrying out phagocytosis of damaged neuropil and cells. In specimens from the two patients who were studied five and 11 days after injury, extensive leucocyte and microglial phagocytosis was seen and deposition of collagen fibres was prominent

Table 3 Microvillus counts (SEM) and pinocytotic vesicle activity (TEM) after contusion

\begin{tabular}{|c|c|c|c|c|}
\hline & \multirow{2}{*}{$\begin{array}{l}\text { Time interval } \\
\text { after } \\
\text { injury }\end{array}$} & \multirow{2}{*}{$\begin{array}{l}\text { Endothelial pinocytotic } \\
\text { vesicle count } \\
\text { per } \mu^{2} \\
\text { mean }(S D)\end{array}$} & \multicolumn{2}{|c|}{$\begin{array}{l}\text { Luminal microvillus counts per } 25 \mu^{2} \\
\text { mean }(S D)\end{array}$} \\
\hline & & & Capillaries $(<10 \mu)$ & $(>10 \mu)$ \\
\hline $\begin{array}{l}\text { Controls } \\
\text { Contusion }\end{array}$ & $\begin{array}{l}- \\
3-6 \text { hours } \\
13-23 \text { hours } \\
24-48 \text { hours } \\
2-5 \text { days } \\
11 \text { days }\end{array}$ & $\begin{array}{l}6 \cdot 105(3.51) \\
6 \cdot 125(2 \cdot 99) \\
4 \cdot 72(3.01) \\
1 \cdot 5(0.91)\end{array}$ & $\begin{array}{l}9.66(3.77) \\
2.92(1.59) \\
0.75(0.45) \\
5.343(2.44) \\
7.166(2.23) \\
7.91(2.33)\end{array}$ & $\begin{array}{c}12.916(3.81) \\
22.19(5.6) \\
5.0(2.5) \\
4.914(1.35) \\
8.45(3.45) \\
12.31(3.63)\end{array}$ \\
\hline
\end{tabular}


Figure 8 High magnification thin section taken five days after cerebral contusion. Note numerous endothelial microvilli and accumulation of glycogen granules in astrocytic perivascular foot processes (a). (Magnification: $\times 26000$ ).

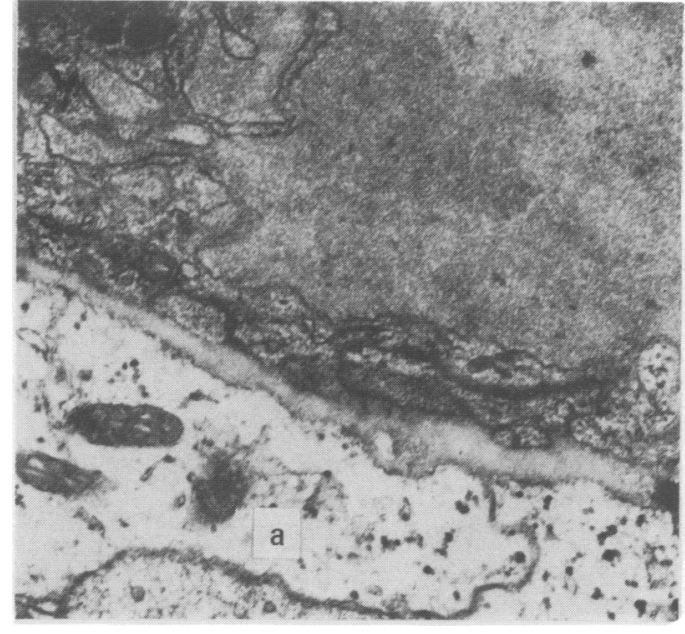

Figure 9 Thin section of a pyknotic cortical cell, probably a neuron containing lipofuscin granules, taken 72 hours after head injury. Note marked shrinkage and peri-cellular vacuolation. Magnification: $\times 11000)$.

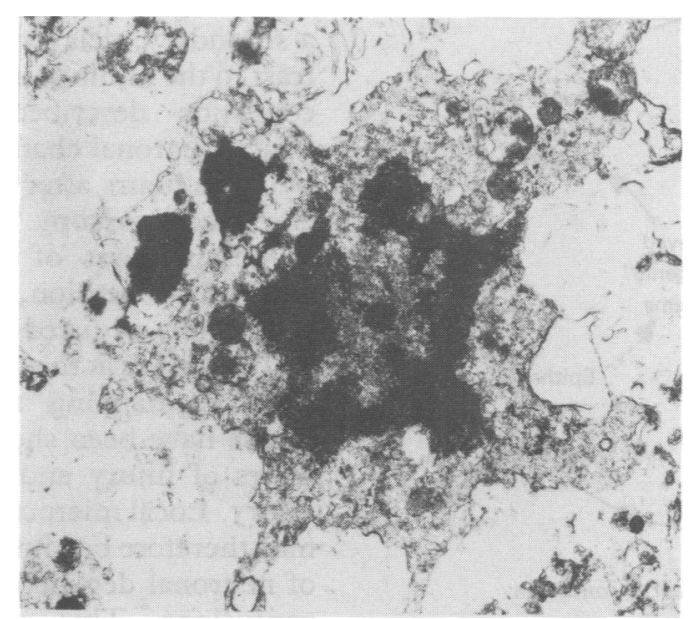

Figure 10 Thin section from cortical neuropil in patient $R S 11$ days after head injury. Note leucocytic phagocytosis (M) collagen fibre deposition (outline arrow) and fibroblast $(F)$ (Magnification: $\times$ 9250).

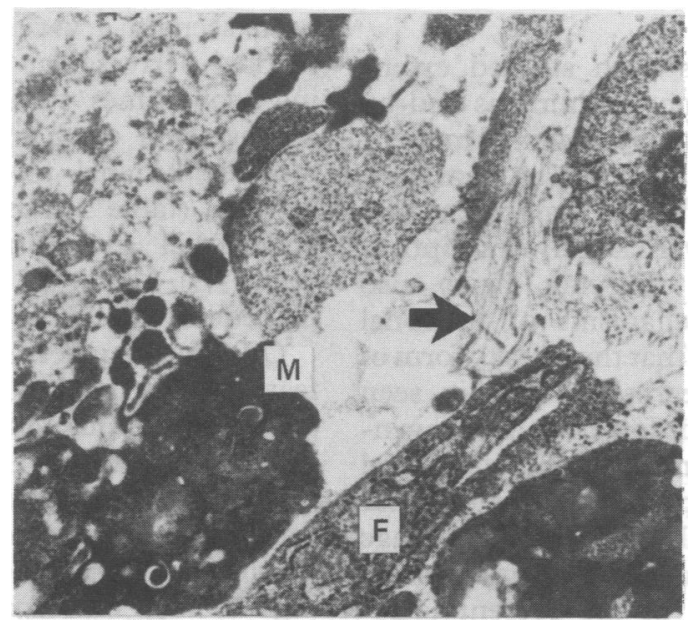

the neuropil in tissue adjacent to cerebral contusions was particularly noticeable on scanning EM in comparison with the control patients (fig 3).

\section{B VASCULAR AND PERIVASCULAR CHANGES}

Vessel morphology was remarkably normal in all specimens studied. Tears in vessel walls were not seen. Blood clots occluding the lumen of vessels were seen only occasionally, although this may relate to the vibration and ultrasonication process which was used to visualise the lumina. In many vessels, however, adherent red cells and leucocytes were found suggesting an abnormality of endothelial adhesion characteristics. Red cells were seen moving through fenestrations in the endothelial membrane to leave the vessel lumen, by a process of diapedesis (fig 11a, b)

Perivascular accumulations of red blood cells were a frequent finding and in several specimens, these caused streak-like disruption of tissue architecture.

\section{Pit-vesicle activity}

Pit-vesicle activity was present in both control and contusion specimens, but was less extensive in the patients with contusions. In some areas, the endothelial luminal membrane was disrupted by coalescent vesicles to form irregular holes in the vessel walls, and in two specimens, red cells were seen passing through these (fig 11a, b). Pit-vesicle activity in the endothelium was always accompanied by parallel development of microvillus formation, but the proportion of pit-vesicle and microvillus activity was variable from specimen to specimen, and no clear relationship was seen, either to time after injury, or to other microscopic changes. When the number of luminal microvilli per $25 \mu \mathrm{m}^{2}$ were counted using SEM, and correlated with the number of vacuoles within the endothelial cytoplasm seen on transmission electronmicroscopy, (table 3) no relationship was seen in either the contusion or control material.

The mean number of endothelial micropinocytotic vesicles in control patients was 6.105 $\mu \mathrm{m}^{2}$ and $6.125 \mu \mathrm{m}^{2}$ in contusion patients at three hours after injury, $4.72 \mu \mathrm{m}^{2}$ at $24-48$ hours after injury, and $1.5 \mu \mathrm{m}^{2}$ at five days after injury. Thus there was a slight (but not statistically significant) decline over time in the number of endothelial pinocytotic vesicles in damaged tissue.

Marked changes in luminal microvillus (fig 10), indicating the early stages of scar tissue formation. In the patient studied 11 days after injury, perivascular foot process swelling was absent and the numbers of perivascular microglia were increased, suggesting that the stage of maximal cell swelling had been passed.

Findings on scanning electronmicroscopy in patients with cerebral contusion

A NEUROPII

The vacuolated "Swiss cheese" appearance of activity were seen in the contusion material, at various times after injury (table 3 ). In capillaries, microvilli numbers dropped to their lowest levels when astrocytic and foot process swelling was most marked, at 13-24 hours and slowly rose to near control values by 11 days. By contrast, in larger vessels microvillus activity rapidly rose to almost twice control levels in the first six hours after injury, then dropped to nearly a third of control levels at 2448 hours, and were approaching control levels by 11 days. 
Figure 11 (A) Scanning EM preparation of the luminal surface of $a$ cortical arteriole taken 17 hours after head injury. Note the large fenestrae in the endothelial surface through which erythrocytes are seen to pass (arrow). (Magnification: $\times 1780$ ); (B) High magnification view of the endothelial surface 17 hours after head injury. Note the endothelial microvilli and erythrocyte passing

through the fenestration.

(Magnification: $\times$ 9700).
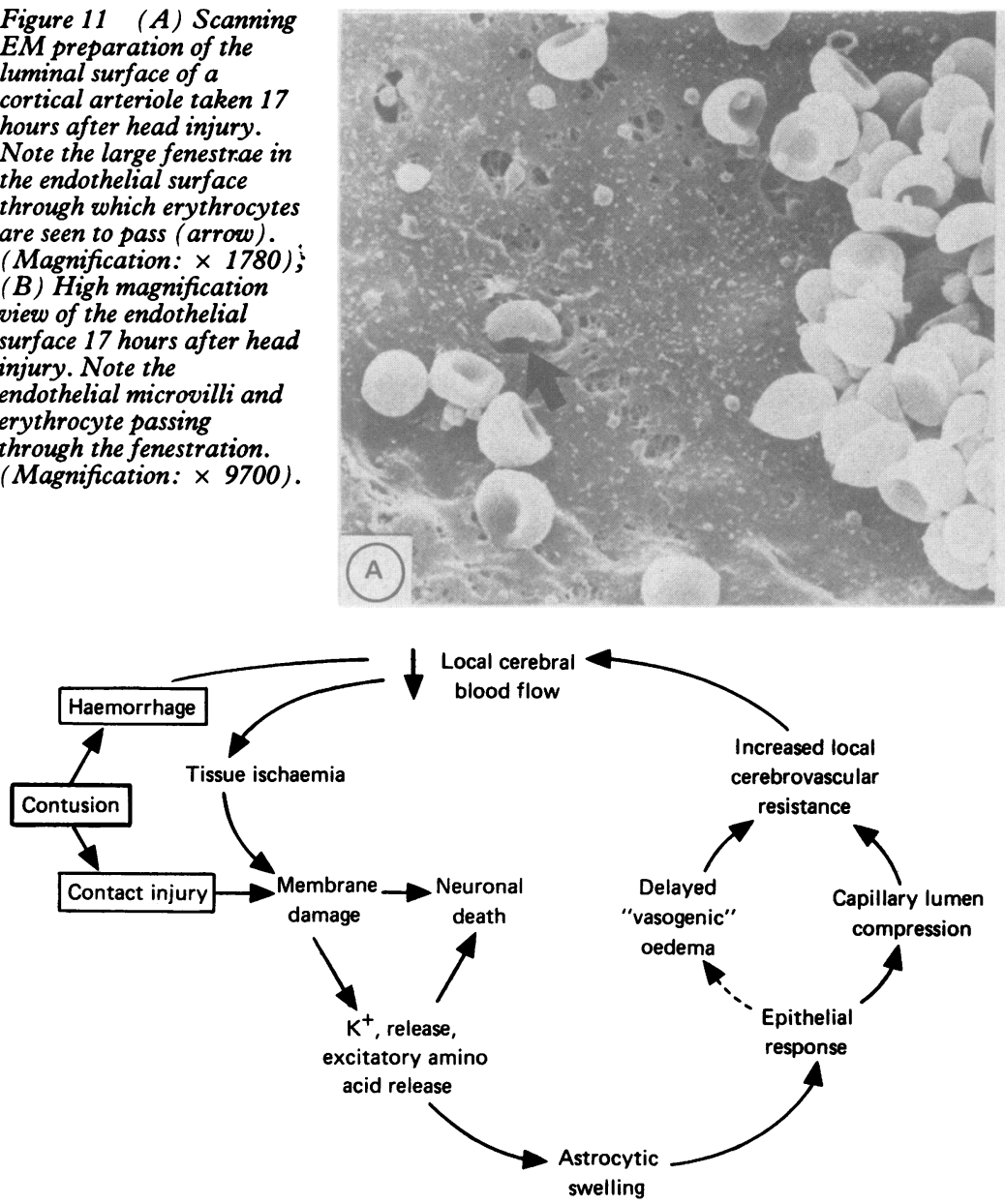

Figure 12 Possible pathophysiological mechanisms after cerebral contusion.

\section{Discussion}

Cerebral contusion has been studied extensively by light microscopy in humans and by light and electronmicroscopy in animal models, but the ultrastructural changes in humans have not been reported. ${ }^{1-5}{ }^{10-12}$ The majority of histopathological studies were largely descriptive, but Lindenberg and Freytag have also speculated on the mechanisms of neuronal damage. It is postulated that the streaky form of neuronal ischaemic necrosis which is seen surrounding contusion differs from the conventional changes of ischaemia, ${ }^{413}$ and postulated that impact injury propagates waves of shear stress through brain substance which damage neurons by tearing axons and dendritic processes. ${ }^{5}$ However, neither in the present ultrastructural study nor in that of Hekmatpanah in a rat model could shearing of dendritic processes or axons be demonstrated. ${ }^{11}$ Moreover, the neuropathological studies of Adams and Graham carried out in 635 patients dying after severe head injury have not documented an association between either retraction balls or microglial stars, the hallmarks of diffuse axonal injury, and cerebral contusion. ${ }^{14}$

In this study, neurons demonstrating the features of the ischaemic cell process were not seen in the specimens taken at three and six hours, but were clearly apparent in the specimens taken at one day; by the third day, pyknosis and nuclear lysis were obvious (fig 9). This suggests that the neuronal degeneration

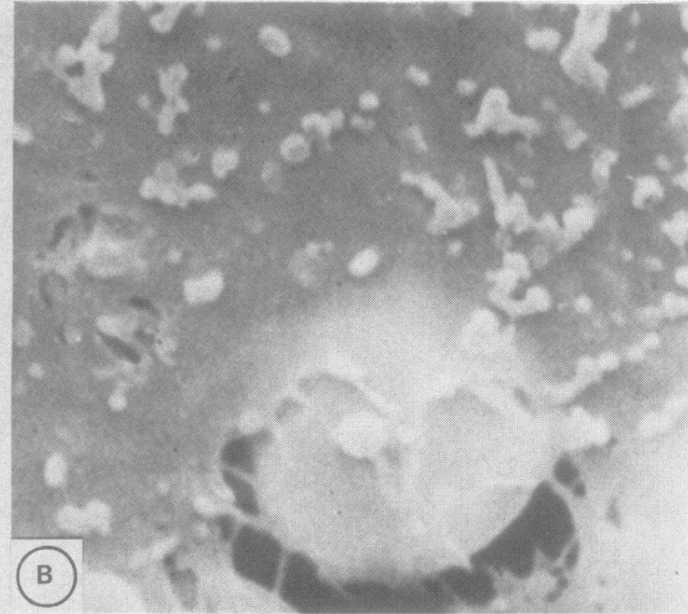

which occurs after contusion in humans may be a secondary, delayed process. This is in contrast to the findings in the rat model of cerebral contusion described by Hekmatpanah, in which neuronal changes were well established by three hours after injury, both on light and electronmicroscopy. ${ }^{11}$

Measurement of rCBF in patients after cerebral contusion, has shown zones of profoundly reduced CBF (around 15-20 ml/ $100 \mathrm{gm} / \mathrm{min}$ ), at the site of the contusion, using SPECT mapping and PET techniques. ${ }^{815}$ These have been shown as early as within 24 hours of injury and up to three weeks after injury. Local microcirculatory vascular factors may therefore be important in the pathogenesis of neuronal degeneration adjacent to cerebral contusions. This study demonstrates four major microvascular changes, which have also been seen in a variety of animal models: 1) marked perivascular astrocytic process swelling-sometimes sufficient to cause apparent compression of the vessel lumen (fig 4);2) reduced luminal pit-vesicle and microvillus activity, (table 3; figs 7 and 8); 3) decreased endothelial cytoplasmic vacuole formation (table 3), and 4) transvascular red cell diapedesis (fig 11).

Our study suggests that the major structural feature associated with reduced local tissue perfusion is microvascular collapse and compression due to astrocytic perivascular podocytic process swelling together with some compromise of cerebral circulation mediated by the development of endothelial microvilli (figs 4, 11). This accords with our previous ultrastructural findings, those of Dietrich et al, and the pattern of profound perifocal reduction in $\mathrm{rCBF}$ seen in a model of intracerebral haematoma. ${ }^{8121617}$ Perivascular astrocytic podocyte swelling was also prominent in the ultrastructural studies of Allen-performed in a primate model of high velocity missile injury, and Hekmatpanah, in the rat contusion model. ${ }^{1011}$ We have not, however, seen the vessel tears and thrombosis described by Hekmatpanah in the rat model, and we have not demonstrated disruption of inter-endothelial tight junctions (fig 7).

Although the specimens studied five days after injury showed less marked astrocyte cell body and foot process swelling than those 
studied within the first few days, these changes should be interpreted with caution. Serial biopsies were not taken from the same patient and the severity of the contusion was variable from patient to patient.

For these reasons the mechanisms by which perivascular astrocytic foot process swelling may resolve after a contusion cannot be inferred from this study. Although specimens taken at five days or more after the injury show evidence of astrocytic process sprouting, and apparent reconstitution of the foot process limiting membranes, (fig 6a) this may represent the response to a less severe lesion. To improve our understanding of these fundamental repair mechanisms, serial biopsy studies will be needed, in an animal model, with a controlled severity of injury.

Early perifocal oedema has been demonstrated in microgravimetric studies after human contusion. ${ }^{1819}$ The prominence of astrocytic swelling early after cerebral contusion, and the integrity of the inter-endothelial tight junctions seen in this study and in animal models, ${ }^{10112021}$ suggests that this is a cytotoxic process. The relative paucity of protein-rich extracellular fluid (except where gross tissue disruption was present), (fig 5) within the neuropil in this study is also evidence against a vasogenic mechanism.

This agrees with the results of studies of blood-brain barrier permeability which we have performed at various time intervals after focal cerebral contusion in 20 patients. SPECT scanning after intravenous ${ }^{99 \mathrm{~m}} \mathrm{Tc}$ pertechnetate, showed that blood-brain barrier changes were seldom detectable before three days after injury, and were maximal at about 10 days. $^{8}$

The micro-anatomical basis for the delayed development of increased vascular permeability after contusion is difficult to determine from this study, or from the animal studies of other authors. Povlishock, using a fluid percussion model of head injury, demonstrated that Horseradish peroxidase (HRP) passed rapidly through intact endothelial cells after intravascular injection, and accumulated beneath the basement membrane, and within endothelial vesicles. ${ }^{212}$ HRP was found chiefly within endothelial cytoplasmic vesicles and the number of vesicles increased rapidly within 15 to 30 minutes after trauma. ${ }^{21}$ In contrast to these experimental observations, we have demonstrated that after a contusion micropinocytotic vesicles decline in number with time (table 3). Therefore, it is unlikely that micropinocytosis is an important mechanism in delayed post-contusional oedema.

The role of pit-vesicle activity and microvillus formation after head injury is not understood. Its presence within hours of injury after "pure" diffuse axonal injury suggests that it may be a non-specific response to the invariable hypertensive surge which occurs within seconds after severe head injury. ${ }^{23-25}$

We have observed coalescence of vesicles to form ragged holes in the endothelial luminal membrane, through which intact erythrocytes are seen to pass (fig 11). This partly accords with other studies, ${ }^{22}$ and may provide a mechanism for the peri-vascular accumulation of erythrocytes, which is a frequent histological feature after contusion but which has not been previously explained. ${ }^{145}$ Vessel tears may therefore not be necessary for perivascular "haemorrhage".

Although we and other authors have shown that astrocytic swelling is well established after cerebral contusion as early as three hours after injury, both in this study and in animal models, the cause for this swelling remains uncertain. ${ }^{10-12} 2022$

When cerebral blood flow falls sufficiently low to cause failure of neuronal energy metabolism, and membrane depolarisation (around $14-15 \mathrm{ml} / 100 \mathrm{gm} / \mathrm{min}$ ) due to global or focal ischaemia, massive astrocytic swelling occurs as a buffering mechanism; astrocytes absorb free $\mathrm{K}^{+}$ions in an attempt to maintain extracellular fluid homeostasis. ${ }^{26}$ Global ischaemia is, however, unlikely to occur as a very early event after focal human contusion and, moreover, some animal studies have shown blood pressure and CBF to be transiently elevated after head injury. ${ }^{23} 25$

Faden et al and Becker et al have demonstrated massive release of excitatory amino acids after fluid percussion injury, in tissues immediately beneath the impact point, but not distant from it. ${ }^{2829}$ Excitatory neuronal membrane depolarisation may result from this glutamate release, to cause subsequent $\mathrm{K}^{+}$ion flooding of the extracellular space, and this may cause astrocytic swelling, which itself may jeopardise focal tissue perfusion adjacent to a cerebral contusion, and induce further ischaemic damage. ${ }^{26} \mathrm{~A}$ pathological "vicious cycle" such as that shown in fig 12 , may thus be postulated, as a cause for neuronal death in cerebral contusion.

Vasoconstrictor substances such as $\mathrm{K}^{+}$, serotonin, or prostaglandins may also be released into the contused tissue, inducing the profound fall in regional blood flow, which we have demonstrated on SPECT (8).

Further studies are needed to clarify the causes of astrocytic swelling, and to explore the possibilities of therapy for preventing or attenuating this astrocytic response, which may be detrimental to neuronal survival.

We are grateful to the neurosurgeons at the Institute of Neurological Sciences, Glasgow who assisted with obtaining cerebral contusion and control specimens, and to Anne Semple for preparing the manuscript.

1 Adams JH, Gennarelli TA, Graham DI. Brain damage in non-missile head injury: observations in man and subhuman primates. In: Thomas Smith W, Cavanagh JB, eds Recent advances in neuropathology. Edinburgh: Churchill Livingstone, 1982:165-90.

2 Adams JH, Gennarelli TA, Graham DI, et al. Changes in endothelial morphology of brain vasculature after controlled angular acceleration of the subhuman primate head. Proc Physiological Soc 1987:92.

3 Adams JH, Scott G, Parker L, et al. The Contusion Index: a quantitative approach to cerebral contusions in head quantitative approach to cerebral contusions in
injury. Neuropathol Appl Neurobiol 1980;6:319-24.

4 Lindenberg R, Freytag E. Morphology of cortical contusions. Arch Pathol 1957;63:23-42.

5 Lindenberg R, Freytag E. The mechanism of cerebral contusion. Arch Pathol 1960;69:440-69.

6 Miller JD, Gudeman SK, Kishore PS, et al. Computed tomography in brain oedema. Advances in neurology Vol 28. New York: Raven Press; 1980:413-22.

7 Levin HS, Grossman RG, Rose JE, et al. Longterm neuropsychological outcome in closed head injury. 
Neurosurg 1979;50:412-22.

8 Bullock R, Teasdale GM, Wyper D, et al. Tomographic mapping of CBF, CBV and BBB changes after focal head injury using SPECT: mechanisms for late deterioration. In: J Hoff, ed. Proc VIIth Int Symposium Intracranial Pressure and Brain Injury. Berlin: Springer-Verlag 1989:637-9.

9 Torvick R, Skjorten F. Electron microscopic observations on nerve cell regeneration and degeneration, after axon on nerve cell regeneration and degeneration, after axon Neuropathol 1971;17:248-64.

10 Allen IV, Kirk J, Maynard RL, et al. An ultrastructura study of experimental high velocity penetrating head injury. Acta Neuropathologica (Berl) 1983;59:277-82.

11 Hekmatpanah J, Hekmatpanah CR. Microvascular alterations following cerebral contusion in rats. $J$ Neurosurg 1985;62:888-97.

12 Jenkins A, Maxwell WL, Graham DI. Experimental intracerebral haematoma in the rat: sequential ligh microscopical changes. Neuropathol Appl Neurobiol 1989;15:477-86.

13 Little JR, Kerr FWL, Sundt TM. Microcirculatory obstruction and focal cerebral ischaemia: an electron microscopic investigation in monkeys. Stroke 1976;7(1):25-30.

14 Adams JH, Doyle D, Ford I, et al. Diffuse axonal injury in head injury. Definition, diagnosis and grading. Histopathology 1989;15:49-59.

15 Tenjin H, Mizukawa N, Yamaki T, et al. The investigation of cerebral haemodynamics in patients with cerebra contusion: Evaluation of Positron Emission Tomography (PET). J CBF Metabol 1989;9(Suppl 1):S87.

16 Dietrich WD, Busto R, Ginsberg MD. Cerebral endothelia microvilli and fenestration following global fore brain ischaemia. J Neuropathol Exp Neurol 1984;43:72-83.

17 Mendelow AD, Bullock MRR, Teasdale GM, et al. Intracranial haemorrhage induced at arterial pressure in the rat. Pt II. Short term changes in local cerebral blood flow measured by autoradiography. Neurol Res 1984;6:189-93.

18 Bullock MRR, Smith R, Favier J, et al. Brain specific gravity and CT density measurements after human head injury. $J$
Neurosurg 1985;63:64-8.

19 Galbraith S, Cardoso E, Patterson J, et al. The water content of white matter after head injury in man. In: Go KG, Baethmann A. Recent progress in the study and therapy of brain oedema. New York: Plenum Press, 1984:323-9.

20 Olsson Y, Rinder L. Studies on vascular permeability changes in experimental brain concussion. Acta changes in experimental brain concus

21 Povlishock JT, Becker DP, Sullivan HG, et al. Vascular permeability alterations to horse radish peroxidase in experimental brain injury. Brain Research 1978;153: 223-39.

22 Povlishock JT. The morphopathologic responses to experimental head injuries of varying severity. In: Becker DP, Povlishock JT, eds. CNS Trauma Status Report. Bethesda, Maryland: NIH, 1986:443-52.

23 Gennarelli TA, Segawa H, Wald U, et al. Physiological response to angular accelaration of the head. In: Grossmann RG, Gildenberg PL, eds. Head Injury: basic and clinical aspects. New York: Raven Press 1982:129-39.

24 Maxwell WL, Irvine A, Adams JH, et al. Response of the cerebral microvasculature to brain injury. $J$ Pathology 1988;155:327-35.

25 Nilsson $\mathrm{B}$, Nordstrom $\mathrm{CH}$. Experimental head injury in the rat. Pt 3. Cerebral blood flow and oxygen consumption after concussive impact acceleration. $J$ Neurosurg after concussive

26 Bourke RS, Nelson KM. Further studies in the $\mathrm{K}+$ dependent swelling of primate cerebral cortex in vivo: the enzymatic basis of the $\mathrm{K}+$ dependent transport of chloride. $J$ Neurochem 1972;19:663-85.

27 Plum F, Cooper AJL, Craig RP, et al. Glial cells: the silent partners of the working brain. The Thomas E Duffy Memorial Lecture. J CBF and Metabol 1985;5(Suppl 1):S1.

28 Becker DP, Katayama Y, Tamura T, et al. Excitotoxic ionic fluxes and neuronal dysfunction following traumatic brain injury. J CBF Metabol 1989;9(Suppl 1):302.

29 Faden AI, Demediuk P, Panter SS, et al. The role of excitatory amino acids and NMDA receptors in traumatic brain injury. Science 1989;244:798-800. 